\title{
Study of Staff Training at Educational Hospitals by Qualitative Approach
}

\section{ALIREZA RAJABIPOOR MEYBODI and FAHIMEH FORGHANI}

Department of Economics, Management and Accounting, Yazd University, Yazd, Islamic Republic of Iran.

\section{Abstract}

The essential resource for all organizations, mostly educational hospitals, for coping with changes is training of human resources. Staff training is accepted not only as an inevitable necessity for the growth and survival of the organization but also as part of the culture of the organization. That is why the research's main goal is to extract and classify concepts in the training of Staff the method of study was qualitative and had an inductive approach. In this regard, after reviewing the research context using semi-structured interviews, the data collected and analyzed. Considering this research's purpose, which is to design a staff-training model in educational hospitals, in-depth interviews were conducted with 13 experts in this field. In three stages, open coding, axial coding, and selective coding were performed. The thematic analysis technique was used to analyze the data from researchers' interviews in a peaceful environment and identify the model. A further advantage, particularly from learning and teaching, is that it is a method rather than a methodology. To ensure the Quality of the findings, the process of extracting concepts and coding monitored by expert researchers. Based on the results obtained from the software, training needs, training targets, training methods, training effectiveness, and educational hospitals identified by 58 codes. The results show that assessing needs of educational hospitals is the highest priority for staff training criteria.

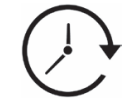

Article History

Received: 25 June 2021

Accepted: 08 September 2021

\section{Keywords \\ Educational Hospitals; \\ Staff Training; \\ Training; \\ Thematic Analysis.}

\section{Introduction}

Human resources considered the most important asset of organizations and their competitive advantage in the current era (Campbell, 2016). Improving human resources knowledge, abilities, and skills is essential for organizations to deal with the changes (Demirk, 2012). Staff training is considered a critical and strategic issue for organizations. It is seen as a tool by which organizations determine the range in which their human capital is considered sustainable (Gary and Peters, 2016). Training is one of the topics that man has been working on it for ages. With the emergence of communities and the creation of jobs, organizations, and hospitals, staff

CONTACT Alireza Rajabipoor Meybodi $\bigotimes_{\text {rajabipoor@yazd.ac.ir }} \boldsymbol{9}_{\text {Department of Economics, Management and Accounting, Yazd }}$ University, Yazd, Islamic Republic of Iran.

\section{(cc) (i)}

(C) 2021 The Author(s). Published by Enviro Research Publishers.

This is an Open Access article licensed under a Creative Commons license: Attribution 4.0 International (CC-BY).

Doi: http://dx.doi.org/10.12944/JBSFM.03.01-02.12 
training became more vital and today the survival of organizations is tied to it. The present age is associated with rapid change, and every day a new change occurs in the world of business. In the meantime, organizations must either accompany them with those changes or witness their death and destruction. (taghipoor et al., 2016).

Continuous training is the key to development in organizations, and the effects of training on the success of educational and research hospitals are not overlooked. Hospitals should always work efficiently and effectively to help Staff and managers develop their skills to develop creative ideas and improve their services (weru et al., 2014). Training in educational hospitals is a fundamental and ongoing task and not an interim task for educational hospitals that use innovative training methods and developing their Staff. They would have a better performance compared to the organizations which do not use such methods. Staff training helps organizations cope with competitive challenges (Kennedy, 2015).

Parsons et al. (2012) conducted a study entitled Evidence-Based Staff Training: A Guide for Practitioners. This study provides a proven approach to teaching functional skills training that can assist behavior analysts in successfully training work skills related to human service personnel.

That is why organizations have increasingly focused on training their human resources, and the increasing number of training person-hours and per capita training arepieces of evidence of this claim (Asiayi, 2015). Due to the acceleration of change and increasing competition, organizations are more than ever trying to achieve results and preserve themselves. Designing an appropriate educational model for these two purposes (achieving results and maintaining survival) is significant. "Because this is training that improves organizational performance and excellence (Ahamdi et al., 2015). In other words, instructional design as a scientific domain, which teaches how to provide training opportunities for learning in organizations, plays a crucial role in organizations. So, some believe that instructional design is the core part of any educational effort (Karagiorgi, 2005). Changing the paradigm from an industrial economy to a knowledge-based economy and creating an independent spirit for problemsolving amongst staffs, lack of association between training and career activities, lack of attention to critical factors in the training process, organizations' increasing emphasis on staff training, problemoriented approach to Staff occupational design, are the most critical factors which demonstrate the need for providing a unique training model for staffs in educational hospitals (Jennings, 2016)

Organizations are mechanisms or tools to achieve the goals of society, in other words, tools and programs that are designed and implemented to meet the basic needs of society (Rajabipour, 2018). Investigating the formation and transformation of organizations shows that in the past, due to the simplicity of human life and technology, the scope of organizations' structures and functions was simple and primitive, and individuals did not need to have professional knowledge of their activities (Rowden, 2007). The changes made in social life later became widespread in the organization's various dimensions, making their goals, tasks, and responsibilities more complicated and making them even more challenging to manage. The consequence of such massive industrial, technological, economic, and.. Changes in the nineteenth and early twentieth centuries made the organization vital (Clifford, 2007). According to the United Nations Educational, Scientific and Cultural Organization (UNESCO), education is all actions, influences, way, and means for working out and developing brain and cognitive abilities and the skills, attitudes, and behaviors of humans. However, in such a way that excels man's personality as much as possible and makes man the positive value of the society in which he lives (Tavakoli, 2008).

Training is an experience based on learning intended to make permanent changes in one to improve himself to perform more effectively (Imran, 2013). Training is one of the most potent weapons we have to build the future. It is inevitable for a human to consider it, since at the dawn of the new century, with the ever-increasing development of communications, exchange of information in a broader level, has made profound changes in social roles if individuals, and as a result, man needs to acquire information in a more organized way. According to the facts mentioned above, training is one of the most critical management tools to increase organizational efficiency. Regarding the importance of training in the restoration and improvement 
of human resources as the most critical integral element of each organization, managers should provide the necessary support for the organization's training (Rahimian et al., 2017).

In all these definitions, training is the critical factor in human excellence, and this excellence can be useful in the relationship between employees and management. The role of learning in recent organizations has been of great interest, and understanding the learning process and how it affects one's future behavior is useful. That is why many organizations allocate considerable resources for staff training. All problematic human behaviors achieve through learning (Khorasan, 2013). If managers want to justify, predict, or control a person's behavior, they need to know how they learned it. (Saeed et al., 2014). A common weakness in many performance management systems is that managers and supervisors do not pay enough attention to staff training and ultimately do not receive the necessary feedback. Human resource training is a lucrative investment that pays off in the flourishing and development of the organization and plays a vital role in excelling society's culture. The term training is an integral part of the working life principle in any organization, and its main aspects are cultivated skill development and professional expertise. The establishment and continuity of training in today's organizations have an essential role to play in the profession and, in fact, in the organization to be led. Staff training is vital and inevitable and should be continuously noticed along with other management processes so that other management activities can be useful. Training is one of the principals and logical methods of leading staff efforts in organizations and helps hidden talents within organizations flourish and use imagination; moreover, Staff may feel more mentally flexible. That is educating and training human resources, which helps a country to achieve self-sufficiency. However, we should never forget this critical point that training, with all its importance and necessity, can be practiced only when it is in line with the physical, spiritual, psychological, and future needs of Staff and does not contradict them. If done correctly, comprehensive, and thoroughly, staff training can be used to achieve specified goals and can have countless benefits for the organization. Most essential advantages include facilitating achieving organizational goals, qualitative and quantitative improvement of products or services provided by the organization, creating harmony in the way tasks are handled, reducing probability of accidents and incidents in the workplace, improving morale of the personnel and stabilizing the organization can be mentioned (Grossman, 2011), reducing direct and indirect supervision reducing conflicts, rebellion, absenteeism, and other abusive group behaviors in the workplace, reducing public expenditures in an organization, including maintenance costs, prime costs, service costs or recruitment costs (Ghafar, 2016), increasing in profitability and efficiency and allocating the profit for employees' welfare, preventing duty and responsibility conflicts, reinforcing the sense of loyalty and solidarity, flourishing staff' latent talents, creating a sense of flexibility in Staff, creating a platform of growth and success in occupational, social, individual fields (Salas et al, 2012).

Human resource training is a lucrative investment that pays off in the flourishing and optimal development of the organization and plays a vital role in excelling society's culture. The term training is an integral part of the working life principle in any organization, and its main aspects are cultivated skill development and professional expertise. The establishment and continuity of training in today's organizations have an essential role to play in the profession and, in fact, in the organization to be led. Before defining instructional design, defining the components forming this expression (Design and instructional) separately is necessary. "Designis a rational, logical, and sequential process for problem-solving. Due to this, the design process can be recognized as the problem-solving process (Crawford, 2004). In his article, Michael Spector (2000), "Towards a Philosophy of Instruction," has defined instruction as supporting and facilitating learning. Reigeluth (1997) stated a similar definition and defined instruction as "whatever is done to help an individual learn."

Organizations may be successful regardless of the design and implementation of staff training models. However, this is different from educational hospitals. There are a few educational hospitals that are successful without an instructional design model. In educational hospitals, practical design and staff training, implementation are likely to lead to better education and up-to-date and practical learning. 
This is what the philosophy of educational hospitals is (demark, 2012).

Smith et al. (2019) in their study entitled "Redesign of Hospital Diabetes Education: A Quality Assessment with Nursing Teams" examined the barriers and facilitators of web-based education for patients with diabetes among nursing units. In relation to training programs, through semi-structured interviews with physicians, nurses and health workers, the subject of training programs and models, content capabilities of the platform, and workflow reviews and considerations related to skills training were identified.

On the other hand, the best instructional design model in the world may lead to no positive change in an organization; due to other issues such as payment and poor conditions, inefficient systems, governmental regulations, economic situations, and (Gary and Peters, 2012). If the instructional design in an organization is worthwhile, the link between instructional design and performance improvement should be clear. The instructional design should be precise, elegant, scholarly, and professional. However, if it does not lead to performance improvement, there would be low or no value for employers and employees (Okin, 2015). Instructional Design in an organization is a broad and diverse system and should help visible and measurable skill development. However, skill development does not necessarily lead to better overall performance or results in an organization. The instructional design should be focused on what the learner can understand or do to improve organizational goals (no one, 1993). Higher education tends to promote knowledge on the one hand and create new knowledge on the other. It is considered the subject of teaching theories and very young and unique (yarmohammadian, 2015). Higher education represents an essential type of investment in human resources that contributes to economic development by enhancing the knowledge, skills, and attitudes required for senior technicians, experts, and managers. Universities and other educational hospitals contribute more to the economy. Economists consider staff training as a type of investment. In the past, training and development were not recognized as activities that could help organizations provide value and face challenges successfully. Nowadays, this mentality has changed. Organizations that benefit from innovative training and development methods are likely to perform better than those who do not use such methods. Training and development also help organizations to cope with competitive challenges better (Sagnak, 2015). Organizations should always rely on effective and efficient training to help their Staff and managers improve and develop their skills to improve and provide genuine and innovative ideas to deliver high-quality services. Also, development and job placement management is essential for preparing employees for managerial and leadership positions and attracting, motivating, and retaining employees at all levels and in all occupations.

Barton et al. (2018) conducted a study entitled Teaching nurses teamwork: Integrative review of competency-based team training in nursing education. During their study, 19 people were selected and evaluated using quantitative and qualitative evaluation tools and a regular comparative approach. Nursing teamwork knowledge is rooted in the theory of highly reliable teams and crisis management resources. Constructive training is used to practice and improve teamwork skills. Assessing nursing teamwork is complex. This includes the integrated determination of individual knowledge, skills and attitudes. Future initiatives should include front-line leadership, supportive commitment, and an emphasis on skillful communication. Collective stakeholder support is needed to transform teamwork competencies into nursing.

Mobilizing and preparing human resources are especially important for coping with changes since human resources are considered strategic capital. According to their goals and mission, all organizations, mainly educational hospitals, should allocate most financial and time resources to training in various dimensions. Therefore, the integration of these trainings with the changes in the future requirement of the workplace. Training is the most critical process for transferring knowledge to organizations' Staff and help them carry out their tasks effectively. Excellent and practical training would increase job satisfaction, enhances abilities, and reduces teleworking. This will not happen unless all organizational hierarchies understand the importance of training and Staff recognize it as a means for their and their organizations' development. The primary role of training is to change the way 
people think and behave. Organizations' success derives from the proper and effective use of scarce resources, especially human resources, and their attention to hospital staff training (Clifford, 2007). Professional training within the workplace indicates complex individual and organizational processes (Ellinger, 2007), described as the relationship between two essential processes of working and learning. In organizational training, occupational activities would become a part of learning, and learning would turn into a part of the occupation. Training in organizations usually focuses on developing key competencies or improving individual and organizational performance(Imran, 2013).

\section{Research Methodology}

The current qualitative research is applied in terms of objective and is content-oriented. The method for collecting theoretical backgrounds data and information in this study is desk research. For collecting and presenting media entrepreneurial patterns, it has been field research and in-depth interview. The thematic analysis technique was used to analyze the data from researchers' interviews in a peaceful environment and identify the model. The main areas, which have been examined during the interviewing experts, are as follows: What factors do you consider, as a specialist, if you want to design a staff training model for educational hospitals? What are the strengths and weaknesses of current staff training models in educational hospitals? What do you think about staff training objectives? What should educational hospitals do to understand and determine the exact training need of the Staff? Do you have any suggestions for a better understanding of those needs? What training methods do you propose for employees?

Table 1: Demographic information

\begin{tabular}{ccccccc}
\hline I.D. & $\begin{array}{c}\text { Background in } \\
\text { Higher Education }\end{array}$ & $\begin{array}{c}\text { Background } \\
\text { in education }\end{array}$ & Gender & Age & $\begin{array}{c}\text { Level of } \\
\text { Education }\end{array}$ & Row \\
\hline M1 & Available & Available & Male & 72 & PhD & 1 \\
M2 & Available & Available & Male & 58 & PhD & 2 \\
M3 & Available & Available & Male & 55 & PhD & 3 \\
M4 & Available & Available & Male & 47 & PhD & 4 \\
M5 & Available & Available & Male & 41 & PhD & 5 \\
M6 & Available & Available & Male & 38 & PhD & 6 \\
M7 & Available & Available & Male & 36 & PhD & 7 \\
M8 & Available & Available & Female & 35 & PhD & 8 \\
M9 & Available & Available & Female & 40 & PhD & 9 \\
M10 & Available & Available & Male & 43 & M.S. & 10 \\
M11 & Available & Available & Male & 47 & M.S. & 11 \\
M12 & Available & Available & Male & 49 & M.S. & 12 \\
M13 & Available & Available & Female & 55 & M.S. & 13 \\
\hline
\end{tabular}

Therefore, in this research, the samples were first selected purposively, based on their scientific research records (Articles, books, etc.) And their executive responsibilities, especially in the field of education and higher education. Subsequently,by conducting in-depth interviews with 13 experts who had scientific and executive background in training and reaching the theoretical saturation criterionin Iranian hospitals, no new code was received after the 11th interview, but two more interviews were conducted for assurance. Individual in-depth interviews lasted between 60 to 90 minutes with each participant. Then, by analyzing and interpreting the qualitative and studying existing theories on staff training, its components and indicators were identified and collected.According to Goba and Lincoln (1985), to obtain the research's validity, four criteria of credibility, transferability, dependability, and conformability have been considered. To validate the samples, interviews were revised to verify the data. With sufficient time spent by the researcher, confirmation of the research process by 
five experts, the use of two coders to codify multiple interviews to ensure that the coders' views are the same have increased the reliability of the research data to an acceptable level. To ensure the research findings' transferability, two more experts who have not participated in the research were consulted about the research findings. Data analysis was conducted about the qualitative nature of the information obtained from the interview and the extraction of similar concepts in them using qualitative data coding method, taking into account the stages of data browsing, a compilation of coding guidance, data organization, data classification, open coding, Axial coding, a compilation of final report and analysis of qualitative data. This process begins with studying the verbal statements of the interviewees using MAXQDA 12. After reading each interviews' script, some parts of it were highlighted, which could be considered the primary code based on research objectives. Subsequently, factors were identified.

Table 2: Classification of Fundamental concepts

\begin{tabular}{|c|c|c|c|}
\hline Fundamental Concepts & $\begin{array}{l}\text { Organizational } \\
\text { Concepts }\end{array}$ & $\begin{array}{l}\text { Inclusive } \\
\text { Concepts }\end{array}$ & \\
\hline Training before starting the job & Organizational & Educational & Staff \\
\hline Organization analysis & Needs & Needs & Training \\
\hline Job analysis & Assessment & Assessment & Model \\
\hline Inquiries from the Staff & Individual Needs & & \\
\hline Not to be prescribed by superiors. & Assessment & & \\
\hline $\begin{array}{l}\text { Comparing the performance of individuals with } \\
\text { other Staff }\end{array}$ & & & \\
\hline $\begin{array}{l}\text { The increasing commitment of Staff } \\
\text { Improving intra-organizational communication }\end{array}$ & $\begin{array}{l}\text { Organizational } \\
\text { Goals }\end{array}$ & $\begin{array}{l}\text { Instructional } \\
\text { Goals }\end{array}$ & \\
\hline
\end{tabular}

Reducing accidents and incidents and improving

products and services

Organization Growth and Development

Scoring the Staff

Achieving organization policy

Organizational culture improvement and change

transferring and sharing knowledge

Application of knowledge

Knowledge

Goals

Increasing motivation

Attitude

The growth of Staff self-efficacy

Goals

Inter-personal communication

Professional tasks

Staff's efficient use of responsibilities and powers

Class presentation methods

Attendance Training

Lectures, seminars, conference, workshop, ... methods

Skill Goals

Job rotation

On-the-Job training

Self-learning and self-development

Non-

Correspondence training

attendance 
Interaction between learner and sources through

communication channels

Technology-based training

Virtual learning

Pre-execution evaluation

Evaluation during execution

Post-execution evaluation

Harmony between Staff instructional needs and

instructional contents

Learning/training process quality

Outputs and outcomes of Quality

Decreasing expulsion and resignation

Reducing administrative offenses

Increasing job satisfaction

Spending the least possible budget

Minimizing staff absenteeism

Minimizing waste of time by the instructor and ...

Pre, during, and post-evaluation and tracking studies.

Evaluating On-the-Job Training

Staff academic and continuous assessment

The program should not be boring for learners.

The program should not be a waste of time.

Can measure their changes

Learners' residences

Catering and services

Instructors' mastery of teaching methods and techniques Up-to-date education and experience

Effective presenting abilities

Providing a general course timetable

Providing the opportunity for attending courses outside

of the organization

Informing Staff about courses through SMS, Email, and

staff automation system

Issuing certifications and diplomas

Allocating sufficient time

Allocating sufficient funding
E-learning

Evaluation Time

Instructional

Evaluation

Efficiency

Effectiveness

Performance

External

Evaluation

Self-

assessment

Space \&

Equipment

Educational

Facilitie

Competent

Instructors

Planning and

Execution
Budget \&

Credit

\section{Results and Discussion}

In educational hospitals, practical design and staff training, implementation are likely to lead to better education and up-to-date and practical learning. This is what the philosophy of educational hospitals is (demark, 2012). If the instructional design in 
an organization is worthwhile, the link between instructional design and performance improvement should be clear. The instructional design should be precise, elegant, scholarly, and professional.

Considering this research's purpose, which is to design a staff-training model in educational hospitals, in-depth interviews were conducted with 13 experts in this field. In three stages, open coding, axial coding, and selective coding were performed. The following table is the result of qualitative data analysis.

\section{Training Needs Assessment}

The first stage in planning education for Staff is a training needs assessment. Training need assessment is a tool by which we determine whether any training is needed or not and what kind of training is needed, and to whom. Training needs assessment is conducted by using different methods like observation, interviews, questionnaires, etc. The needs assessment is an elementary stage in training planning because only through precise identification of training needs, major dimensions in in-service training programs can be specified (ljeoma, 2016). Although needs assessment is a critical issue in training planning, it is done less objectively, and assessment of needs is often done subjectively (Manley, 2014). Once needs assessment is carried out correctly, i.e., needs are identified realistically, the training programs based on such assessment can comply with reality. They can be useful in solving individual and organizational problems. Training needs can be behavioral needs, felt needs, expressed needs, comparative needs, anticipated needs, or expected needs. Organizational goals and values are critical in need assessment.

\section{Training Goals}

Education of Staff consists of continuous, organized actions to achieve specific goals of improving knowledge and awareness, boosting job skills, and promoting proper behavior by stable society's stable values. The education also aims to help the organization reach its objectives (Gary and peters, 2016). Objectives of the training that why we are conducting training, what outcomes will it bring to the organization, and how it will lead to the organization's effectiveness. Setting objectives define the standards to measure the performance of trainers and trainees after conducting the training. Knowledge sharing, Knowledge application, and Knowledge creation were classified in Knowledge goals. Knowledge sharing is an activity through which knowledge (namely, information, skills, or expertise) is exchanged among people, friends, families, communities (Cook, 2000).Knowledge application is when available knowledge is used to make decisions and perform tasks through direction and routines. Knowledge creation is an endless process that includes creating and recognizing new ideas and models, combining separated rules, and devising new processes to create knowledge (Levin and Cross, 2004).Motivation, positive psychology, and problem-solving skills are three keywords in training goals. Problem-solving skills refer to our ability to solve problems effectively and timely without any impediments (D'Zurilla, 2002). Positive psychology is "the scientific study of what makes life most worth living," or "the scientific study of the positive human functioning and flourishing on multiple levels that include the biological, personal, relational, institutional, cultural, and global dimensions of life" and motivation refers to "the reasons underlying behavior."

\section{Training Methods}

There are various instructional methods for training staff. However, they can be categorized into three general attendance, non-attendance, and electronic methods. The electronic method is based on technology. It provides instruction without the time and places limits for the Staff. This method is based on the reciprocal instruction between the learner and the instructional resources through a communication network. Virtual learning is active, and intelligent learning has significant relevance in supporting and promoting formal education in an organization (Siemens, 2012).

\section{Training Evaluation}

Evaluation is the systematic collection, analysis, and interpretation of information, aiming at determining the extent of achievement (Buys, 2012). Research on education effectiveness indicates that encouragement and training programs lead to increased innovation and enhancement of skills among Staff. Education plays a vital role in recognizing and training the innovative ability of the Staff. 
After the proper implementation of the training program, the next step is to evaluate both trainer's and trainees' performance right after the program and observe trainees' performance after few months of training to utilize the techniques they learned during training. It will make us aware of whether our training program has proved effective or not. By this, we will come to know about the weaknesses and strengths of our training program (Woodard, 2016). external evaluation and self-assessment are two types of training evaluation. The organization does external evaluation and self-assessment done by Staff.

\section{Training Facilities}

Thus, a training program's elements include materials, place of training, time, participants, trainer (Allen, 2003), instructional equipment, instructional lessons, instructional activities, management and logistics, and budget (Weng, 2017). Relationships were identified in figure 1.

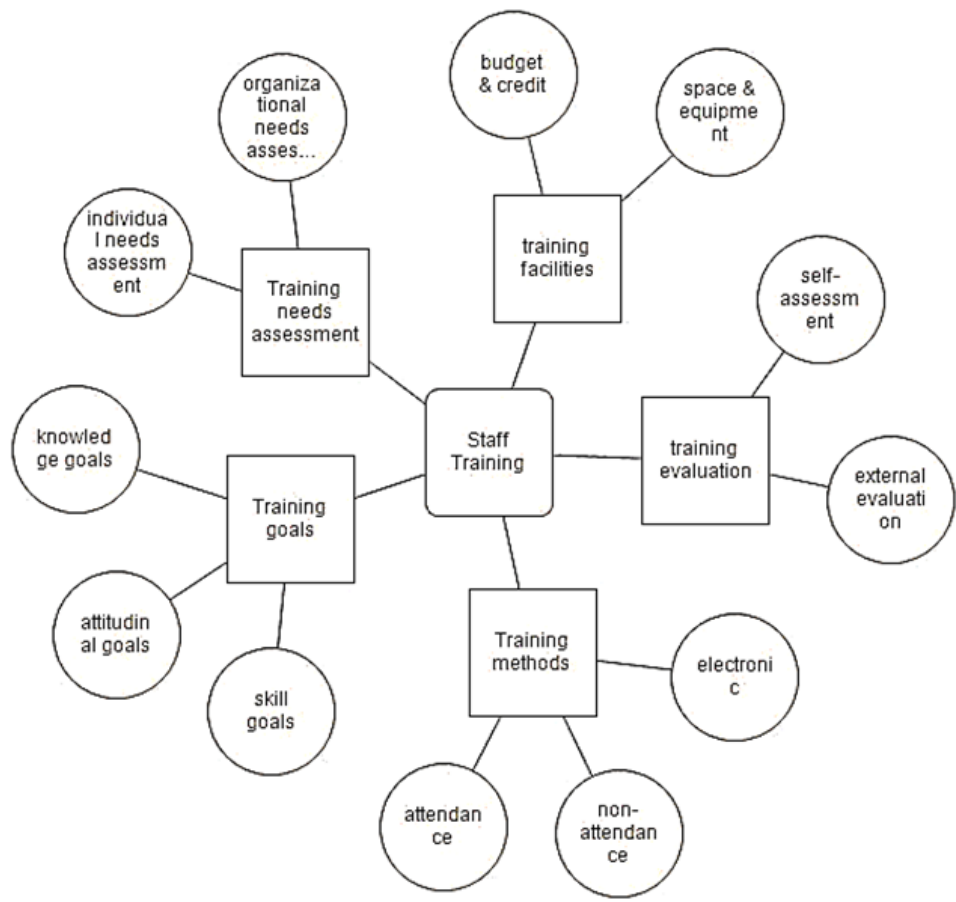

Fig.1: the content network (Maxqda output)

\section{Research Objectives}

Human resources are the strategic capital of any organization. Their training is vital and unavoidable and should be constantly considered along with other management processes to make other management activities useful. Training is one of the main and logical methods to guide the efforts of employees in organizations and helps to develop the talents hidden in organizations and use the imagination. Having an educational model makes it better in the organization. Therefore, this study aims to design a comprehensive model for education, especially in teaching hospitals, which includes the goals and needs of staff.

\section{Conclusion}

The purpose of this study was providing a model for staff training in educational hospitals. In a transcendental organization, employees have the task of self-learning, apart from playing an organizational role. As a result of thought exchange, skills would grow so that everyone would play an essential role in his colleagues' development. Thus, the competencies of Staff are completed, and experts improve them and their organization's knowledge. On the other hand, the content of the training itself would become dynamic. The richness of the contents delivered would increase every day and prevent job repetition and organizational 
errors.Resources, contents, and training topics in the form of classrooms, seminars, conferences, visits, field trips, academic exchanges, discussions, documented meetings of strategic committees and experts, library resources, Internet searches, databases and software systems, if this information and knowledge are instructed for self-efficient Staff, research-based and training spirit will be created amongst Staff and organizational learning, will take place and interactive and challenging environment, will be created between Staff and their occupation; therefore, the richness of jobs will be increased, and competency matrix for succession planning and talent management will be provided.

In their study, Chen et al. (2008) investigated the effect of the instructor's role and interaction in the staff training process. Lee et al. (2007) examined the impact of content, evaluation, and environmental, Chong et al. (2005) examined the effect of selflearning contents, the method of presenting lessons, assignments, and evaluations, Martinez Carrow (2008) studied learners interaction. The interaction between learners and instructor in staff training, Issyk (2008) investigated the impacts of usability, value-added for customers, self-efficacy of the computer on staff satisfaction from learning, Kurt et al. (2005) studied the position of educational content production. Peng et al. (2006) examined the effect of educational facilities, instructors, and educational content on staff satisfaction.Sullivan et al. (2021) suggested that the network approach to education promotes growth and success and facilitates the standardization of plans and the training of specialized nurses. It is suggested that to achieve a more practical model of the final research model, quantitative validation of the model should be implemented, and necessary modifications to the model should be made.

\section{Acknowledgment}

We would like to thank the managers and staff of the studied hospitals for their cooperation.

\section{Funding}

No grants were received, the expenses were from a personal place.

\section{Conflict of Interest}

The authors do not have any conflict of interest.

\section{References}

1. Ahmadi, J., Bahmei, J., Ranjbar, M., Rahimi, H., \&Shahbazi, H. (2015). Study Of Relationship Between Organizational Climate And Faculty Members' Participation In Academic Decision Makings. Journal of Payavard Salamat, 9(2), 118-130. and Social Sciences,3(9): 57-75

2. Asiyai, R. I. (2015). Improving Quality Higher Education in Nigeria: The Roles of Stakeholders. International Journal of higher education, 4(1), 61-70.

3. Barton, G., Bruce, A., \& Schreiber, R. (2018). Teaching nurses teamwork: Integrative review of competency-based team training in nursing education. Nurse education in practice, 32, 129-137.

4. Buys, N. A. (2012). The role of management in practical knowledge and skills transfer. [Dissertation], South Africa: University of Johannesburg. South Africa.

5. Campbell, A. (2016). " Talking Point"--Flexible Targeted Online Staff Development That Works. Journal of Interactive Media in Education,
2016(1).

6. Clifford, J, \& Thorpe, S. (2007). Workplace Learning \& Development: Delivering Competitive Advantage for Your Organization. Kogan Page.

7. Cook, M. (2000), The Convergence of Knowledge Management and Business Intelligence, Auerbach Publications, New York, USA.

8. Crawford, C. (2004). Non-linear instructional design model: eternal, synergistic design and development. British Journal of Educational Technology, 35(4), 413-420.

9. Demirk, N. (2012). Academic ethic in Turkish universities: Perceptions of academicians from engineering medicine and education colleges. Eurasian Journal of educational research, P.P. 41-60.

10. D'Zurilla, T. (2002). Program is Correct, but it does not Run: A Preliminary Social problem-solving inventory-revised: Technical Investigation of Novice Programmers' Problems. Manual. Toronto, ON, Canada. 
11. Ellinger, A. \&Cseh, M. (2007). Contextual factors influencing the facilitation of others' learning through everyday work experiences. Journal of Workplace Learning, 19, (7), 435-452.

12. Gary, B; Peters, D. (2016). Assistant Principals' Perceptions Regarding the Role and the Effectiveness of an Educational Leadership Program. International Journal of Higher Education, P.P. 37-62.

13. Ghafar, A. (2016). Impact of Best HRM Practices on Retaining the Best Employees: A Study 011 Selected Bangladeshi Firms. Asian Journal of Social Science and Management Studies, 3, (2), 108-1 14.

14. Grossman, R., \& Salas, E. (2011). The transfer of training: Rut matters. International Journal of Training and Development, 15, (2), 103-120.

15. Imran A, (2013), The Effect of Training on Employee Performance, European Journal of Business and Management, Vol.5, No.4, pp.137-147

16. Jennings, C \&Heijnen, V. (2016). 70:20:10 Towards $100 \%$ Performance. Maastricht: Sutler Media press.

17. Karagiorgi, Y., \&Symeou, L. (2005). Translating Constructivism into Instructional Design: Potential and Limitations. Educational Technology \& Society, 8 (1), 17-27.

18. Kennedy, M (2015) Towards a Taxonomy of System Dynamics Models of Higher Education, Library Management, 23(2), 1-12.

19. Khorasani, \&, donate, (2013). Evaluation of Quality in an educational institute: a quality functions deployment approach. Educational Research and Reviews

20. Levin, D. Z., \& Cross, R. (2004). The strength of weak ties you can trust: The mediating role of trust in effective knowledge transfer. Management science, 50(11), 1477-1490.

21. Manley, L., \& Holley, R. P. (2014). Hiring and training work-study students: A case study. College \& Undergraduate Libraries, 21(1), 76-89.

22. Okin, NP; Kwaba, J G; (2015). The Role of Leaders in Transforming Learners and Learning in the Higher Learning Hospitals in Kenya. Journal of Education and Practice, 16(25), PP 105-116.

23. Parsons, M. B., Rollyson, J. H., \& Reid, D. H. (2012). Evidence-based staff training: A guide for practitioners. Behavior analysis in practice, 5(2), 2-11.

24. Rahimian, H., Abaspour, A., Taheri, M., Kermani, M. and Najafi, A (2017). Study and analyze instructional design patterns and learning in the work environment and select an adaptive model for improving organizational training in Petrochemical Industry, Journal of Human Resources Management in Oil Industry.

25. Rajabipour, M. A., \& Hosseini, E. (2018). Examining the effect of unlearning in the organization on human resource development.

26. Rowden, R. W. (2007). Workplace learning: Principles and practice. Malabar, FL: Kriegr Publishing

27. Saeed, B. B., \& Wang, W. (2014). Sustainability embedded organizational diagnostic model. Modern Economy, 2014.

28. Saeed, B. B.; Wang, W. \& Peng, R. (2014). Diagnosing organizational health: a case study of Pakistani banks. International Journal of Information Systems and Change Management, 7(1), 43-69.

29. SAĞNAK, M., KuruÖz, M., Polat, B., \&Soylu, A. (2015). Transformational leadership and innovative climate: An examination of the mediating effect of psychological empowerment. Eurasian Journal of Educational Research, 15(60), 149-162.

30. Salas, E., Tannenbaum, S. I., Kraiger, K., \& Smith-Jentsch, K. A. (2012). The science of training and development in organizations: What matters in practice Psychological science in the public interest, 13(2), 74-101

31. Siemens, G., \&Gasevic, D. (2012). Guest editorial-learning and knowledge analytics. Journal of Educational Technology \& Society, 15(3), 1-2.

32. Smith, K. M., Baker, K. M., Bardsley, J. K., McCartney, P., \& Magee, M. (2019). Redesigning hospital diabetes education: a qualitative evaluation with nursing teams. Journal of nursing care quality, 34(2), 151.

33. State Owned Corporations, International Journal of Academic Research in Business Sullivan, C. E., Segovia Weber, L., Viveros Lamas, P., Metzger, M. L., Rodriguez?Galindo, C., \& Day, S. W. (2021). A sustainable model for pediatric oncology nursing education and capacity building in Latin American hospitals: Evolution and impact of a nurse educator 
network. Pediatric Blood \& Cancer, e29095.

34. Taghipour, Soleimanlranzadeh E., AlaviMatin Y., (2016), investigating the effect of on-the-job skills training on improving Marine Knowledgebased industries' reliability mediating role of human resources empowerment, Journal of Marine Science Education, 10(4)

35. Tavakoli Sh. (2008), The necessity of on-thejob training courses evaluation in librariesa practical approach in human resource management, Master's Thesis of the Ferdowsi University of Mashhad

36. Weng, C., \& Ackerman, E. (2017). Towards sustainable partnership: examining cross perceptions of public and technical services academic librarians. Library Resources \& Technical Services, 61(4), 198.

37. Weru J et al, 2014, The Relationship between Training and Development on Performance of

38. Woodard, B.S. (2016), "Training and continual learning for reference staff," in Smith, L.C. and Wong, M.A. (Eds), Reference and Information Services: An Introduction, ABC-CLIO, Santa Barbara, CA, pp. 240-280.

39. yarmohammadian, M. (2015). A model for evaluating the performance of universities; the study Branch of Islamic Azad University: Khoorasgan. Journal of New Approaches in Educational Administration, 22(2), P.P. 19-37. 